\title{
Commentary
}

\section{Building a House upon Sand? Human Trafficking, Forced Labor, and Exploitation of Prostitution in}

\section{S.M.v. Croatia}

\author{
By Gillian Kane, PhD Candidate, School of Law, Queen's University, Belfast, \\ Northern Ireland
}

\section{Introduction}

Agreement on the definition of human trafficking was reached in 2000 with the adoption of the Protocol to Prevent, Suppress and Punish Trafficking in Persons Especially Women and Children, supplementing the United Nations Convention against Transnational Organized Crime. ${ }^{1}$ The Convention defines trafficking in persons as

the recruitment, transportation, transfer, harbouring or receipt of persons, by means of the threat or use of force or other forms of coercion, of abduction, of fraud, of deception, of the abuse of power or of a position of vulnerability or of the giving or receiving of payments or benefits to achieve the consent of a person having control over another person, for the purpose of exploitation. ${ }^{2}$

$1 \quad$ Protocol to Prevent, Suppress and Punish Trafficking in Persons Especially Women and Children, supplementing the United Nations Convention against Transnational Organised Crime (adopted by GA Resolution 55/25 15 November 2000, entered into force 25 December 2003) UNGA Res 55/25 (Palermo Protocol).

2 Ibid., Article 3. Exploitation is defined in a non-exhaustive list within Article 3. Moreover, further clarifications are made in Article $3(\mathrm{~b})-(\mathrm{d})$ : where one of the means identified in Article $3(\mathrm{a})$ is used, consent is irrelevant; as far as children are concerned, only an act and a purpose are required to constitute trafficking. 
The definition includes three elements that must be fulfilled for conduct to amount to human trafficking, namely, an act, a means, and a purpose. ${ }^{3}$ Despite the apparent consensus, discussion has continued as to the definition's precise scope ${ }^{4}$ and the relationship between the concept of trafficking and related concepts, such as slavery, servitude, and forced labor. ${ }^{5}$ On the relationship between trafficking and forced labor, the International Labor Organization's (ILO) position is that "trafficking in persons for the purpose of exploitation is encompassed by the definition of forced or compulsory labor." 6 Moreover, the 2014 Protocol to Convention No. 29 on Forced Labor explicitly requires efforts to combat trafficking for the purpose of forced labor. ${ }^{7}$ Notably, Stoyanova regards the ILO's position as an "erroneous" one. ${ }^{8}$ These differing positions demonstrate that consensus on the conceptual boundaries of each of the elements of trafficking has yet to be reached.

In S.M. v. Croatia, the European Court of Human Rights' (ECtHR) Grand Chamber engaged anew with the discussion on trafficking and its conceptual proximity to or overlap with the terms in Article 4 of the European Convention on Human Rights (ECHR), namely, slavery, servitude, and forced labor. The issue centred upon whether Croatia had fulfilled its procedural obligations under Article 4, and the holding of the Court on this matter should not be overlooked. ${ }^{9}$ The focus in this article, however, is the Court's analysis of the material scope of Article 4, especially the place of trafficking within such material

3 See, inter alia, ECtHR (Grand Chamber), S.M. v. Croatia, Application no. 6o561/14, 25 June 2020, para. 114 .

4 See, for example, Vladislava Stoyanova, Human Trafficking and Slavery Reconsidered (cup 2017); Jean Allain, "No Effective Trafficking Definition Exists: Domestic Implementation of the Palermo Protocol," Albany Government Law Review 7 (2014): 111.

5 See Anti-Trafficking Review 5 (Special Issue: Forced Labor and Human Trafficking): 2015.

6 ILO, "Report on the Committee of Experts on the Application of Conventions and Recommendations" (Articles 19, 22, and 35 of the Constitution), Report III part IB (101st Conference Session, Geneva 2012), paras. 297, 299.

7 ILO, Po29 - Protocol of 2014 to the Forced Labour Convention, 1930 (adopted 11 June 2014, entered into force 9 November 2016), Article 1(3).

8 Vladislava Stoyanova, "The Grand Chamber Judgment in S.M. v. Croatia: Human Trafficking, Prostitution and the Definitional Scope of Article 4 ECHR," Strasbourg Observers, 3 July 2020, https://strasbourgobservers.com/2020/07/o3/the-grand-chamber-judgment-in-sm-v-croatia-human-trafficking-prostitution-and-the-definitional-scope-of-article-4-echr (accessed 13 September 2020).

9 For further discussion, see Stoyanova, "The Grand Chamber Judgment in S.M. v. Croatia"; and Noemi Magugliani, "S.M.v Croatia: States' positive obligations, internal trafficking, and abuse of a position of vulnerability," 1 July 2020, Irish Centre for Human Rights, https:// ichrgalway.wordpress.com/2020/o7/o1/s-m-v-croatia-states-positive-obligations-internaltrafficking-and-abuse-of-a-position-of-vulnerability (accessed 28 September 2020). 
scope; the connection between trafficking and forced labor; and the relationship between exploitation of prostitution, forced labor, and trafficking. ${ }^{10}$ With previous case-law on trafficking and Article 4 having attracted criticism, ${ }^{11}$ the task faced by the Grand Chamber was to take a step in the direction of clarity. Although it has succeeded in doing this to an extent, the question is whether the clarity that has been achieved is being built on an unstable foundation.

\section{Analysis}

In S.M. v. Croatia, the Grand Chamber reaffirmed that trafficking does indeed fall within the material scope of Article $4{ }^{12}$ noting "good reasons to accept the assertion in Rantsev that the global phenomenon of trafficking in human beings runs counter to the spirit and purpose of Article 4 and thus falls within the scope of the guarantees offered by that provision" ${ }^{13}$ Such reasoning is unsurprising, given the ECtHR's consistent reliance on the 'living instrument' doctrine. ${ }^{14}$ But, what constitutes human trafficking? On this, the Court asserted that "conduct may give rise to an issue of human trafficking under Article 4 ... only if all the constituent elements ... of the international definition of human trafficking are present."15 Accordingly, the decisive factor is whether conduct falls within the definition in the Palermo Protocol. ${ }^{16} \mathrm{~A}$ step in the direction of clarity, perhaps. However, the limits of such clarity become apparent when one recalls that debate continues as to the precise content of each element. ${ }^{17}$ Therefore, reaching agreement on whether conduct amounts to trafficking, and thus falls within the scope of Article 4, may be more complex than it first appears. In question is whether the pursuit of clarity in this area is futile when

10 See 'Separate Opinion of Judge Koskelo' in ECtHR (First Section), S.M. v. Croatia, Application no. 60561/14, 19 July 2018, paras. $18 \mathrm{ff}$.

See, for example, Vladislava Stoyanova, "Dancing on the Borders of Article 4: Human Trafficking and the European Court of Human Rights in the Rantsev Case," Netherlands Quarterly of Human Rights 30, no. 2 (2012): 163. S.M. v. Croatia (Grand Chamber), para. 290.

13 Ibid., para. 292.

14 Ibid., first held in ECtHR, Tyrer v. United Kingdom, Application no. 5856/72, 25 April 1978.

15 S.M. v. Croatia (Grand Chamber), para. 290.

16 Palermo Protocol, Article 3.

17 See, for example, Allain, "No Effective Trafficking Definition Exists: Domestic Implementation of the Palermo Protocol." Allain points to the inconsistencies with domestic interpretation and implementation of the trafficking definition. See also Stoyanova, Human Trafficking and Slavery Reconsidered, $3^{2 f f .}$ 
meaningful consensus on the conceptual parameters of trafficking under the Palermo Protocol has not been established.

This issue may be illustrated further by the Grand Chamber's explanation on the relationship between trafficking and forced labor. As well as observing that "exploitation through work is one of the forms of exploitation covered by the definition of human trafficking," the Court referred to Chowdury and Others v. Greece, in which the "intrinsic relationship" between human trafficking and forced labor was acknowledged. ${ }^{18}$ But what, precisely, is to be understood by this intrinsic relationship? The answer may very well differ according to how one views the content of each of the elements of human trafficking. Stoyanova asserts that though human trafficking "might be comparable" with the concepts in Article 4, "there is no convergence."19 Following such a position, a distinction would arguably always be drawn between human trafficking and forced labor. In contrast, the ILO's position, that trafficking "is encompassed by the definition of forced labor," suggests at least some overlap. ${ }^{20}$

A similar issue is evident in the Court's reasoning on the "exploitation of prostitution" and its relationship with human trafficking and forced labor. Notably, the Chamber had held that both fell within the material scope of Article 4, raising questions about the distinction between the two concepts. ${ }^{21}$ The Grand Chamber took a step away from confusion, explaining that the decisive factor as to whether prostitution falls within the scope of Article 4 is the presence of an element of coercion..$^{22}$ This clarification is welcome but questions remain. Particularly puzzling is the conclusion that forced labor under Article 4 "aims to protect against instances of serious exploitation, such as forced prostitution, irrespective of whether, in the particular circumstances of a case, they are related to the specific human trafficking context." ${ }^{23}$ If the relationship between trafficking and forced labor is intrinsic, and if exploitation of prostitution must contain an element of coercion, it is unclear when precisely forced prostitution would not either be connected to the specific human trafficking context or amount to trafficking. The answer may differ depending on

18 S.M. v. Croatia (Grand Chamber), para. 291, referring to ECtHR, Chowdury and Others v. Greece, Application no. 21884/15, 3o March 2017, para. 93.

19 Stoyanova, "The Grand Chamber Judgment in S.M. v. Croatia".

$20 \quad$ ILO, "Report on the Committee of Experts on the Application of Conventions and Recommendations," paras. 297, 299, referred to in S.M. v. Croatia (Grand Chamber), para. 145 .

21 S.M. v. Croatia (First Section), para. 54; Separate Opinion of Judge Koskelo, paras. $19 \mathrm{ff}$.

22 S.M. v. Croatia (Grand Chamber), paras. $298 \mathrm{ff}$.

23 Ibid., para. 300. 
how one views the conceptual boundaries of trafficking. Arguably, the conclusions of the Grand Chamber, however helpful, require further scrutiny.

Beyond this, an additional aspect of the judgment warrants attention. Significantly, the Grand Chamber clarified that a transnational element is not required for conduct to amount to trafficking. ${ }^{24}$ Relying primarily on an interpretation of the Council of Europe Convention on Action against Trafficking in Human Beings to reach this conclusion, the Court also referred to the Palermo Protocol, explicitly noting that "when read in conjunction with its parent instrument ... the Protocol ... proscribes trafficking irrespective of transnational element or the involvement of an organised criminal group." ${ }^{25}$ For those who assert that the Palermo definition does require a transnational and organized crime context, this assertion may be regrettable. ${ }^{26}$ Nevertheless, the clarification provides certainty that under the ECHR, Article 4 protects those who experience exploitation amounting to trafficking within a purely domestic setting in the same manner as those who are trafficked in a transnational context.

\section{Practical Implications}

This analysis demonstrates that, despite the identified issues, in certain aspects of the S.M. v. Croatia judgment positive steps have been taken toward clarity. Particularly helpful is the confirmation that the Palermo Protocol definition is decisive regarding whether conduct amounts to human trafficking and thus falls within the scope of Article $4 .{ }^{27}$ So, too, are the clarifications on the concept of "exploitation of prostitution," and the explicit acknowledgement that a transnational element is not required for conduct to amount to trafficking. ${ }^{28}$

Nevertheless, although it is arguably now beyond doubt that trafficking falls within the scope of Article 4, uncertainties remain. What precisely is the nature of this intrinsic relationship between trafficking and the concepts

\footnotetext{
24 Ibid., para. 296.

25 Ibid., paras. 119, 162, 294-95. Council of Europe Convention on Action against Trafficking in Human Beings (adopted 16 May 2005, entered into force 1 February 2008) 197 CETS 1, Article 2.

26 See Marika McAdam, "There's no human trafficking or migrant Smuggling without organised crime, the law says - and that matters," OpenDemocracy, 26 February 2020, https://www.opendemocracy.net/en/beyond-trafficking-and-slavery/theres-no-humantrafficking-or-migrant-smuggling-without-organised-crime-the-law-says-and-that-matters/ (accessed 13 September 2020).

27 S.M. v. Croatia (Grand Chamber), para. 303(ii).

28 Ibid., paras. 298, 296, 303(ii).
} 
within Article 4? To what extent, if any, is there convergence between trafficking and forced labor? When could a situation of exploitation of prostitution not be associated with trafficking? Arguably, much of the remaining confusion can be traced back to the lack of consensus on the scope of each element of trafficking within the Palermo definition. ${ }^{29}$ Without returning to the foundation and attempting to create something more solid to build upon, any progress may be likened to a house built on sand-at risk of eventual collapse. ${ }^{30}$ Consequently, the pursuit of clarity on the definition of trafficking and how precisely it connects with forced labor, exploitation of prostitution, and other related concepts needs to continue. It cannot be undertaken solely, or even primarily by the Court. Instead, discussion ought to continue among a wide range of stakeholders, within and beyond the labor law field. Nevertheless, the ECtHR has the potential to play a significant role in creating a more solid foundation as the jurisprudence on trafficking and Article 4 continues to evolve.

29 See discussion in introduction.

30 Notably, critique relating to the foundation upon which ECtHR jurisprudence is built, is found in discussion beyond Article 4 ECHR. See Kathryn Greenman, "A Castle Built on Sand? Article 3 ECHR and the Source of Risk in Non-Refoulement Obligations in International Law," International Journal of Refugee Law 27, no. 2 (2015): $264 \mathrm{ff}$. 